\title{
Peeling the left ventricle as treatment for endocardial fibroelastosis: An exceptional surgical procedure in adults
}

\author{
Thierry Carrel, MD
}

\author{
From the Department of Cardiovascular Surgery, University Hospital, University of Bern, Bern, Switzerland \\ Disclosures: Author has nothing to disclose with regard to commercial support. \\ Received for publication June 14, 2017; accepted for publication June 19, 2017; available ahead of print July 18, \\ 2017. \\ Address for reprints: Thierry Carrel, MD, Department of Cardiovascular Surgery, University Hospital, Bern \\ CH-3010, Switzerland (E-mail: thierry.carrel@insel.ch). \\ J Thorac Cardiovasc Surg 2017;154:e85-6 \\ $0022-5223 / \$ 36.00$ \\ Copyright (C) 2017 Published by Elsevier Inc. on behalf of The American Association for Thoracic Surgery \\ http://dx.doi.org/10.1016/j.jtcvs.2017.06.046
}

In this issue of the Journal, Chan and colleagues ${ }^{1}$ report on an infrequent procedure in an adult patient presenting with endocardial fibroelastosis: namely, peeling off the fibrotic and thickened endocardium to restore compliance of the underlying myocardial tissue. Although Chan and colleagues $^{1}$ describe the surgical technique as acting as a partial "internal decortication" of the ventricular wall, the report itself lacks objective data to suggest that the treatment led to a significant improvement of the myocardial function. Unfortunately, neither basic echocardiographic assessment nor any parameters (not only ejection fraction but also peak e-wave and a-wave velocities, mitral valve a-wave duration, annular velocity, left atrial volume index, and peak tricuspid regurgitation velocity), as recommended by the scientific societies to describe diastolic left ventricular dysfunction, are available. ${ }^{2}$

The approach through the left atrium and the mitral valve was chosen to minimize the potential for additional trauma caused by the exposure itself. With regard to this issue, it can be hypothesized that a transaortic approach would probably have worked as well: the latter approach is more common for those surgeons who are used to performing transaortic resection of hypertrophic obstructive cardiomyopathy. Intraoperative guidance within the left ventricular cavity with a thoracoscopic camera may facilitate the intraventricular work by providing a clear view and eliminating shadows, thus helping to assess the completeness of the resection.

Chan and colleagues ${ }^{1}$ speculated on the possible relationship between endocardial fibroelastosis and mesalamine treatment because of a chronic bowel disease in this patient, or previous myocarditis, which has never been described. They instituted a drug regimen for heart failure according to the American College of Cardiology Foundation and American Heart Association guidelines for the management of heart failure; however, the administration of aldactone, which is known to have beneficial effects in patients presenting with myocardial fibrosis as a manifestation of end-stage heart failure or as

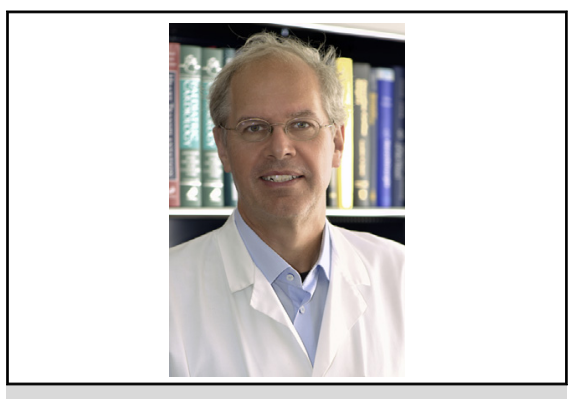

Thierry Carrel, MD

Central Message

Endoventricular peeling of endomyocardial fibroelastosis is when adult cardiac surgeons learn from pediatric cardiac surgeons.

See Article page e81.

a late finding (after radiotherapy, for instance) was not discussed in the article.

Endocardial fibroelastosis is a pathologic entity that is much more common in infants than in adult patients. ${ }^{3-5}$ The etiology is largely unknown, but it may appear secondary to congenital heart disease (eg, left hypoplastic heart syndrome, severe valvular aortic stenosis) and in other restrictive left ventricular but also right ventricular pathologies. Other pathogenetic mechanisms have been reported to play a significant role in the development of endocardial fibroelastosis, such as genetic factors, viral infection, or the transplacental passage of anti-Ro and anti-La antibodies. ${ }^{6}$

Endocardial fibroelastosis should not be confused with endomyocardial fibrosis. Endocardial fibroelastosis is characterized by a thickening of the innermost lining of the heart chambers (but with only the endocardium affected) as a result of an increase in the amount of connective tissue and elastic fibers. It is the most frequent cause of restrictive cardiomyopathy in children along with cardiac amyloidosis and is an uncommon cause of unexplained heart failure in infants and children.

Surgical resection of endocardial fibroelastosis involves removal of the noncompliant fibroelastic endocardial material by sharp dissection. The left ventricle is never opened, because visualization is obtained through the mitral valve or the left ventricular outflow tract. The resection is reminiscent of the excision of a membranous subvalvular stenosis that may be performed sharply with the scissors or 
peeled with a vascular dissector, depending on the adherence of the fibrotic layer with the underlying myocardium.

The literature is extremely scarce on this disease because other types of cardiomyopathy are much more frequent in adult patients. One of those is left ventricular noncompaction cardiomyopathy, which looks completely different, with prominent myocardial trabeculations and deep recesses.

The surgical team of Chan and colleagues ${ }^{1}$ is to be congratulated for being motivated enough to peel this unique form of fibrosis, in analogy to the resection recommended in infants and children with excessive de novo fibrotic subendocardial tissue layer compromising the myocardium. Concerning the restrictive physiology that may impair the growth of the left ventricle in parallel with somatic growth, $\mathrm{Xu}$ and coworkers ${ }^{7}$ demonstrated for the first time that fibrogenic cells within endocardial fibrosis tissue originate from endocardial endothelial cells by way of the endothelium.

\section{References}

1. Chan JL, Rosing DR, Klion AD, Horvath KA. Surgical management of adult endocardial fibroelastosis. J Thorac Cardiovasc Surg. 2017;154:e81-4.

2. Nagueh F, Smiseth OA, Appleton CP, Byrd BF 3rd, Dokainish H, Edvardsen T, et al. Recommendations for the evaluation of left ventricular diastolic function by echocardiography: an update from the American Society of Echocardiography and the European Association of Cardiovascular Imaging. J Am Soc Echocardiogr. 2016;29:277-314.

3. Emania SM, Marx GR. Operations for improving left ventricular diastolic function. Curr Opin Cardiol. 2016;31:101-8.

4. Perez-Negueruela C, Mayor JR, Prada F, Caffarena-Calvar JM. Neonatal Ross-Konno operation and endocardial fibroelastosis resection after fetal percutaneous aortic valve balloon valvuloplasty: a complex approach to rescue the left heart. Eur J Cardiothorac Surg. 2014;46:498-9.

5. Towbin JA, Lorts A, Jefferies JL. Left ventricular non-compaction cardiomyopathy. Lancet. 2015;386:813-25.

6. Pastor Quirante FA, Pastor-Pérez FJ, Manzano-Fernández S, Rivas NL, Pérez PP, Hernández JP, et al. Unexpected autopsy findings after sudden cardiac death: Cardiovascular myxoedema and endocardial fibroelastosis. Nit J Cardiol. 2015; 182:281-3.

7. Xu X, Friehs I, Zhong Hu T, Melnychenko I, Tampe B, Alnour F, et al. Endocardial fibroelastosis is caused by aberrant endothelial to mesenchymal transition. Circ Res. 2015;116:857-66. 